\title{
ChemComm
}

\section{A hybrid porous material from a pillar[5]arene and a poly(ionic liquid): selective adsorption of $\boldsymbol{n}$-alkylene diols $\dagger$}

\author{
Cite this: Chem. Commun., 2014 \\ 50, 2595 \\ Received 29th November 2013, \\ Accepted 13th January 2014
}

DOI: $10.1039 / c 3 c c 49108 k$

www.rsc.org/chemcomm

\author{
Zibin Zhang, ${ }^{a}$ Qiang Zhao, ${ }^{\mathrm{b}}$ Jiayin Yuan, ${ }^{\star \mathrm{b}}$ Markus Antonietti ${ }^{\mathrm{b}}$ and Feihe Huang ${ }^{{ }^{\mathrm{a}}}$
}

\begin{abstract}
A macro-/mesoporous polymeric network with densely incorporated pillar[5]arene functionality was prepared via ionic complexation between a polymerized ionic liquid and carboxylated pillar[5]arene. It retained the solution-state host-guest property of the pillar[5]arene and was successfully applied as a selective absorbent for $n$-alklyene diols.
\end{abstract}

Pillararenes are a new family of macrocyclic hosts. ${ }^{1}$ Their repeating units are connected by methylene bridges at para-positions throughout the ring, thus forming a unique pillar-like architecture. Since the first report in 2008, they have been emerging as powerful macrocyclic hosts, complementing crown ethers, cyclodextrins, calixarenes, and cucurbiturils. ${ }^{1}$ Their highly symmetric, rigid and electron-rich cavities afford them distinctive host-guest complexation with numerous guests. ${ }^{2}$ Pillararenes have been widely used as building blocks in the construction of various supramolecular systems, including supramolecular polymers, ${ }^{3}$ molecular machines, ${ }^{4}$ artificial transmembrane channels, ${ }^{5}$ chemosensors, ${ }^{6}$ functional vesicles ${ }^{7}$ and nanoparticles. ${ }^{8}$

However, up to now almost all studies about the host-guest chemistry of macrocycles have been conducted in solution. ${ }^{9}$ Heterogeneous binding events at solid surfaces are hard to find. This restricts their potential in both fundamental research and industrial applications. Recently, Cooper et al. translated molecular recognition from the solution to the solid state using crystalline molecular organic cages to separate other organic molecules by size and shape. ${ }^{10}$ Inspired by this work, we intend to construct structurally amorphous, but porewise homogeneous hybrid materials by coupling pillararenes in a building block approach towards porous solid-state materials. This may afford a new rational pathway to prepare functional solid sorption materials of controlled porosity and affinity to designated substrates, which then can be used in the separation of structurally similar compounds through powder adsorption, membrane separation and chromatography.

\footnotetext{
${ }^{a}$ State Key Laboratory of Chemical Engineering, Department of Chemistry, Zhejiang University, Hangzhou 310027, P. R. China. E-mail: fhuang@zju.edu.cn

${ }^{b}$ Department of Colloid Chemistry, Max Planck Institute of Colloids and Interfaces, D-14424 Potsdam, Germany. E-mail: jiayin.yuan@mpikg.mpg.de

$\dagger$ Electronic supplementary information (ESI) available: Synthetic procedures, characterizations, crystal data. See DOI: 10.1039/c3cc49108k
}

Poly(ionic liquid)s (PILs) are polyelectrolytes composed of ionic liquid (IL) repeating units. ${ }^{11}$ Their physical properties can be easily and broadly adjusted simply by counterion exchange. This unique merit has enabled a multitude of applications in many fields. ${ }^{12}$ Recently, we created a simple solution method to prepare porous polymer materials via in situ ionic complexation of a PIL, poly(3-cyanomethyl-1-vinylimidazolium bis(trifuoromethanesulfonyl)imide) ( 2 in Fig. 1, PCMVImTf ${ }_{2} \mathrm{~N}$ ) and multivalent carboxylic acids under alkaline conditions. ${ }^{13}$ These porous PIL complex networks with satisfactory specific surface area, large pore volume and stable pore structures have already led to applications in heterogeneous catalysis $^{13 a}$ and adsorption. ${ }^{13 b}$ Here we successfully prepared a porous material 3 with a specific surface area of up to $350 \mathrm{~m}^{2} \mathrm{~g}^{-1}$ based on 2 and a fully carboxylic acid-substituted pillar[5]arene $\mathbf{1}$. This porous material preserved the solution-state host-guest properties of the pillar[5]arene in the solid state and exhibited unique selectivity in adsorption of $n$-alkylene diols.

To prepare the pillar[5] arene-containing porous material 3, 10 wt\% of 2 and 1 (equimolar carboxylic acid and imidazolium units) were mixed in DMSO first, forming a homogeneous solution (Fig. 1). They did not form cross-linked networks by ionic bonding because carboxylic acid groups were electroneutral. When the solution was added dropwise into isopropanol containing $0.5 \mathrm{wt} \%$ of ammonia

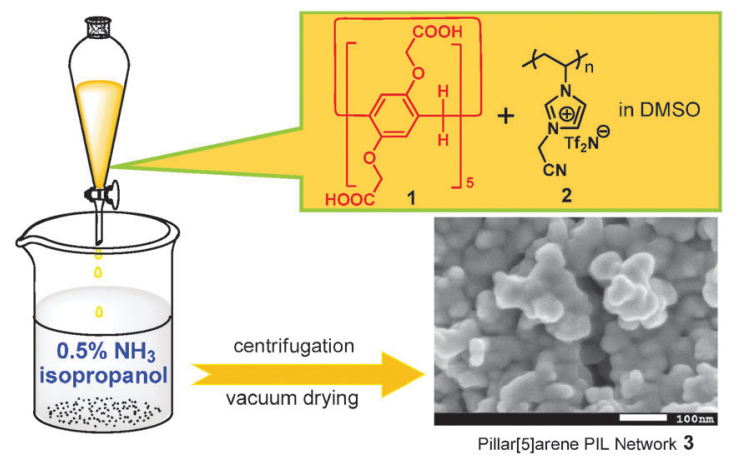

Fig. 1 Synthetic route to and SEM image of porous material 3 based on 1 and 2. 
under stirring and sonication, the $\mathrm{COOH}$ groups were converted into carboxylate anions via deprotonation and initiated the in situ ionic complexation between negatively charged $\mathbf{1}$ and positively charged 2 . It immediately produced the insoluble pillar[5] arene-containing poly(ionic liquid) complex material 3. The precipitate was collected by centrifugation, washed three times, and dried at $50{ }^{\circ} \mathrm{C}$ under high vacuum for $12 \mathrm{~h}$. We used a cross-linked porous poly(ionic liquid) complex material 4 based on 1,2,4,5-benzenetetracarboxylic acid and 2 as a control material (Scheme S3, ESI $\dagger$ ). ${ }^{13 b}$

Fourier transform infrared (FTIR) spectra of 1 and 3 (Fig. S3a, $\mathrm{ESI} \dagger$ ) revealed that the adsorption band at $1710 \mathrm{~cm}^{-1}$ attributed to the $\mathrm{C}=\mathrm{O}$ bonds of the carboxylic acid groups on $\mathbf{1}$ shifted to $1590 \mathrm{~cm}^{-1}$ upon formation of carboxylate anions in 3 . X-ray diffraction measurements of 1 and $\mathbf{3}$ (Fig. S3b, ESI $\dagger$ ) were performed to characterize the solid structures. The diffraction curve of $\mathbf{3}$ has lost the sharp characteristic crystalline peaks of $\mathbf{1}$ and is typical for a slightly ordered, amorphous material. These findings indicated that most of the carboxylic acid groups were converted into carboxylate anions in 3, a noncrystalline solid that is typical for polymeric complexes formed by electrostatic complexation. ${ }^{14}$ Scanning electron microscopy (SEM) was employed to analyze the morphology of 3 (Fig. 1 and Fig. S4, ESI $\dagger$ ). Nano-sized particles $(20-50 \mathrm{~nm})$ as secondary tectonic units are observed. The randomly packed nanoparticles possibly provided the interstitial pore system as large transport channels which increase the mass-transfer efficiency and the specific surface area for heterogeneous binding events.

To further investigate the porous characteristics of 1, 2 and 3, nitrogen sorption measurements were performed (Fig. 2). The isotherms show that the Brunauer-Emmett-Teller (BET) specific surface area and the pore volume of 3 are $350 \mathrm{~m}^{2} \mathrm{~g}^{-1}$ and $1.22 \mathrm{~cm}^{3} \mathrm{~g}^{-1}$, respectively. This indicated that the material is highly porous. The shape of the adsorption and desorption branches showed that the porosity of $\mathbf{3}$ is predominantly surface porosity with large pores in the macropore regime. The latter pores are the lower tail of the interstitial pores. The larger transport pores and the pores inside pillar[5]arene are not accessible by nitrogen sorption. Fig. S5 (ESI $\dagger$ ) depicts the pore size distribution of 3 (calculated by the NLDFT method). In contrast, neither PCMVImTf 2 N 2 nor the fully carboxylic acidsubstituted pillar[5]arene $\mathbf{1}$ shows any detectable porosity themselves (Fig. 2). It is an interesting question if nitrogen sorption really can detect the $c a$. $0.5 \mathrm{~nm}$ sized inner pores of the pillararenes. The sorption isotherm shows no or only very weak indications for those pores, i.e. they are presumably still filled with solvent, which can be tightly

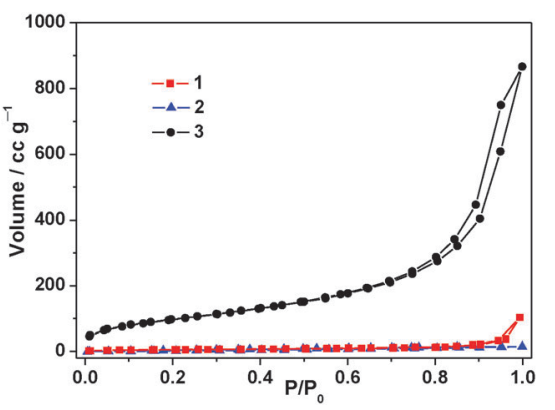

Fig. 2 Nitrogen sorption isotherms of 1, 2 and $\mathbf{3}$. All samples were degassed at $80{ }^{\circ} \mathrm{C}$ for $20 \mathrm{~h}$ before measurements. bound to those cavities. ${ }^{2 k}$ Due to the organic character of the sorption material, vigorous high temperature drying $\left(>150^{\circ} \mathrm{C}\right)$ was not applied.

Based on the reported studies, ${ }^{2 c, d_{i} f, i, 3,4,6}$ the electron rich cavity of the pillar[5]arene can complex neutral guests with linear alkyl groups in solution driven by multiple $\mathrm{C}-\mathrm{H} \cdots \pi$ interactions. For example, dibutoxypillar[5]arene includes $n$-hexane into its cavity to form a pseudorotaxane-type threaded structure in the solid state (Fig. S6a, $\mathrm{ESI} \dagger) .{ }^{2 c}$ Here, in addition to the $\mathrm{C}-\mathrm{H} \cdots \pi$ interactions, two hydrogen bonding donors at the two ends of the guest can be added to strengthen the pillararene-guest interactions (Fig. S6b, ESI $\dagger$ ). Therefore we studied the host-guest binding of a fully carboxylate anionfunctionalized pillar[5] arene 5 and 1,6-hexanediol in $\mathrm{D}_{2} \mathrm{O}$ (Fig. S7, $\mathrm{ESI} \dagger$ ). It is found that all signals from 1,6-hexanediol disappeared, caused by the strong complex-induced increase in relaxation times. Peaks assigned to the aromatic protons of $\mathbf{5}$ shifted significantly downfield. The singlet corresponding to the methylene groups next to the carboxylate anions not only shifted downfield, but also changed to a doublet. These results indicated that the fully carboxylate anion functionalized pillar[5] arene 5 can include 1,6-hexanediol in its cavity in solution. Using the porous material $\mathbf{3}$ as the adsorbent, we studied the adsorption of 1,6-hexanediol in chloroform instead of in the aqueous phase because we found that in water binding analysis is disturbed by the non-selective sorption of alkyl diols by the macro-/ mesopores of the pillararene complex and even the filter (Fig. S8, $\mathrm{ESI} \dagger$ ). For the experiments, we first prepared a $\mathrm{CDCl}_{3}$ solution of $1.00 \mathrm{mM}$ 1,6-hexanediol. The porous material 3 (with $2.50 \times$ $10^{-6} \mathrm{~mol} \mathrm{1}$ ) was added into $1.00 \mathrm{~mL}$ of this solution (with $1.00 \times$ $10^{-6} \mathrm{~mol} 1,6$-hexanediol). The mixture was stirred at room temperature for $1 \mathrm{~h}$, and then 3 was removed immediately by filtration through a PTFE filter into a NMR tube. $1.00 \mathrm{~mL}$ of a pure 1,6hexanediol solution in $\mathrm{CDCl}_{3}$ was filtered through a PTFE filter as a control experiment. By a comparison of their proton NMR spectra (Fig. S9, ESI $\dagger$ ), we found that the peak area of $\mathrm{H}_{1}$ remained the same as that of the original solution through the PTFE filter, thus the filter is non-binding. However, the peak area of $\mathrm{H}_{1}$ decreased by $c a .80 \%$ after being treated with 3 (Fig. S9c, ESI $\dagger$ ). To confirm that this property is really due to the access to the pillararene pores rather than the macromesopores in the complex, we further tested the adsorption capability for 1,6-hexanediol by using equivalent amounts of 1, 2, 3 and 4 (Fig. S10, ESI $\dagger$ ). We found that neither powder 2 nor the porous reference material 4 without pillar[5]arene cavities adsorbed 1,6hexanediol in the $\mathrm{CDCl}_{3}$ solution. Both $\mathbf{1}$ and $\mathbf{3}$ containing the pillar[5] arene were active. The adsorption capacity of 3 is in fact about 4.5 times higher than that of equivalent 1 , which we attribute to the improved access to the pores in the amorphous superstructure as compared to the ground crystalline powder. This means that it was indeed successful in heterogenizing the ability for molecular recognition of pillar[5]arene from the solution to the solid state.

Using the same method, the adsorption kinetics and maximum adsorption capacities of 3 with 1,6-hexanediol were analyzed (Fig. S11, $\mathrm{ESI} \dagger$ ). The affinity of the porous material 3 towards different guests was analyzed from their $\mathrm{CDCl}_{3}$ solutions using the above-described method (Fig. 3). The results showed that $\mathbf{3}$ has the highest affinity to 1,4-butanediol. This agrees well with the work of Li et al. who have revealed that a symmetric guest which contains a linear alkyl chain with four methylenes usually shows the highest binding constant 


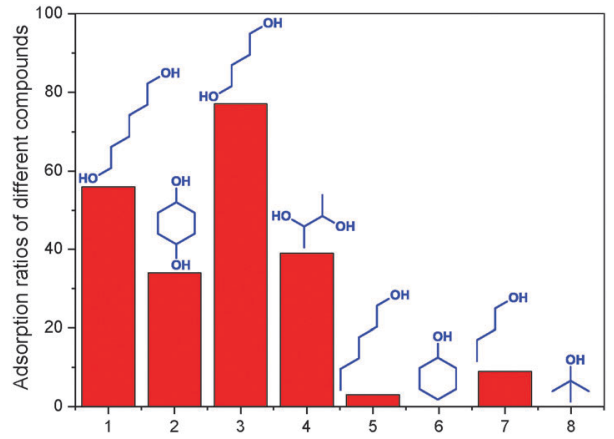

Fig. 3 Percentages bound of different alcohols at $1.00 \mathrm{mM}$ after being treated with 1 equiv. porous material 3

with pillar[5]arenes relative to similar compounds with longer or shorter alkyl chains. ${ }^{2 b, e, i}$ Interestingly, the maximum adsorption capacity of 1,4-cyclohexanediol is only slightly smaller than that of 1,6-hexanediol. The relative binding of 2,3-butanediol is half that of 1,4-butanediol, which is a significant selectivity, but also still a reasonable binding at the same time. More relevant, the porous material 3 showed only a very weak affinity for 1-butanol and 1-hexanol. Finally, 3 cannot adsorb cyclohexanol and tert-butanol at all, because they stretch the host-guest rules too much.

In conclusion, a macro-/mesoporous polymeric material with homogeneous pillar[5]arene cavities was prepared by in situ ionic complexation between a negatively charged pillar[5]arene and a positively charged poly(ionic liquid) in organic solvents. SEM and $\mathrm{XRD}$ results showed that this noncrystalline porous material is composed of secondary nanoparticles, about $20-50 \mathrm{~nm}$ in size, which form a sponge-like superstructure with interstitial meso- and macropores improving liquid transport. Nitrogen sorption measurements revealed a specific surface area of $350 \mathrm{~m}^{2} \mathrm{~g}^{-1}$, and a pore volume of $1.22 \mathrm{cc} \mathrm{g}^{-1}$. On top of this secondary porosity, the pillar[5]arene cavities provide 3 with designated affinities with certain substrates. Binding experiments revealed that at least $80 \%$ of the primary pores are accessible from the outside and are not blocked. The porous hybrid material can for instance adsorb 1,6-hexanediol from $\mathrm{CDCl}_{3}$, whereas a reference complex without supramolecular pores cannot. Variation of the substrate reveals good binding to the family of aliphatic diols, with the highest affinity to 1,4-butanediol. Considering the broad family of pillararenes, the present study not only provides a useful method to introduce host-guest property of macrocycles into solid-state materials but also offers in a more general frame base for the construction of functional materials with controllable affinity to designated substrates.

This work was supported by National Basic Research Program (2013CB834502), the National Natural Science Foundation of China (21125417), the Fundamental Research Funds for the Central Universities and Alexander von Humboldt Fellowship.

\section{Notes and references}

1 (a) T. Ogoshi, S. Kanai, S. Fujinami, T. A. Yamagishi and Y. Nakamoto, J. Am. Chem. Soc., 2008, 130, 5022-5023; (b) D. R. Cao, Y. H. Kou, J. Q. Liang, Z. Z. Chen, L. Y. Wang and H. Meier, Angew. Chem., Int. Ed., 2009, 48, 9721-9723; (c) M. Xue, Y. Yang, X. Chi, Z. Zhang and F. Huang, Acc. Chem. Res., 2012, 45, 1294-1308.
2 (a) C. Han, F. Ma, Z. Zhang, B. Xia, Y. Yu and F. Huang, Org. Lett., 2010, 12, 4360-4363; (b) C. Li, L. Zhao, J. Li, X. Ding, S. Chen, Q. Zhang, Y. Yu and X. Jia, Chem. Commun, 2010, 46, 9016-9018; (c) Z. Zhang, B. Xia, C. Han, Y. Yu and F. Huang, Org. Lett., 2010, 12, 3285-3287; (d) C. Li, S. Chen, J. Li, K. Han, M. Xu, B. Hu, Y. Yu and X. Jia, Chem. Commun., 2011, 47, 11294-11296; (e) C. Li, X. Shu, J. Li, S. Chen, K. Han, M. Xu, B. Hu, Y. Yu and X. Jia, J. Org. Chem., 2011, 76, 8458-8465; $(f)$ L. Liu, D. Cao, Y. Jin, H. Tao, Y. Kou and H. Meier, Org. Biomol. Chem., 2011, 9, 7007-7010; (g) Z. Zhang, Y. Luo, B. Xia, C. Han, Y. Yu, X. Chen and F. Huang, Chem. Commun., 2011, 47, 2417-2419; (h) Z. Zhang, G. Yu, C. Han, J. Liu, X. Ding, Y. Yu and F. Huang, Org. Lett., 2011, 13, 4818-4821; ( $i$ ) X. Shu, S. Chen, J. Li, Z. Chen, L. Weng, X. Jia and C. Li, Chem. Commun., 2012, 48, 2967-2969; (j) S. Dong, B. Zheng, Y. Yao, C. Han, J. Yuan, M. Antonietti and F. Huang, Adv. Mater., 2013, 25, 6864-6867; (k) L.-L. Tan, Y. Zhang, B. Li, K. Wang, S. Zhang, Y. Tao and Y.-W. Yang, New J. Chem., 2014, 38, 845-851.

3 (a) Z. Zhang, Y. Luo, J. Chen, S. Dong, Y. Yu, Z. Ma and F. Huang, Angew. Chem., Int. Ed., 2011, 50, 1397-1401; (b) K. Wang, C.-Y. Wang, Y. Wang, H. Li, C.-Y. Bao, J.-Y. Liu, S. X.-A. Zhang and Y.-W. Yang, Chem. Commun., 2013, 49, 10528-10530; (c) S. Dong, J. Yuan and F. Huang, Chem. Sci., 2014, 5, 247-252.

4 (a) Z. Zhang, C. Han, G. Yu and F. Huang, Chem. Sci., 2012, 3, 3026-3031; (b) Y.-L. Sun, Y.-W. Yang, D.-X. Chen, G. Wang, Y. Zhou, C.-Y. Wang and J. F. Stoddart, Small, 2013, 9, 3224-3229.

5 (a) W. Si, L. Chen, X.-B. Hu, G. Tang, Z. Chen, J.-L. Hou and Z.-T. Li, Angew. Chem., Int. Ed., 2011, 50, 12564-12568; (b) X.-B. Hu, Z. Chen, G. Tang, J.-L. Hou and Z.-T. Li, J. Am. Chem. Soc., 2012, 134, 8384-8387; (c) L. Chen, W. Si, L. Zhang, G. Tang, Z.-T. Li and J.-L. Hou, J. Am. Chem. Soc., 2013, 135, 2152-2155.

6 N. L. Strutt, R. S. Forgan, J. M. Spruell, Y. Y. Botros and J. F. Stoddart, J. Am. Chem. Soc., 2011, 133, 5668-5671.

7 (a) Y. Yao, M. Xue, J. Chen, M. Zhang and F. Huang, J. Am. Chem. Soc., 2012, 134, 15712-15715; (b) G. Yu, C. Han, Z. Zhang, J. Chen, X. Yan, B. Zheng, S. Liu and F. Huang, J. Am. Chem. Soc., 2012, 134, 8711-8717; (c) G. Yu, M. Xue, Z. Zhang, J. Li, C. Han and F. Huang, J. Am. Chem. Soc., 2012, 134, 13248-13251; (d) G. Yu, X. Zhou, Z. Zhang, C. Han, Z. Mao, C. Gao and F. Huang, J. Am. Chem. Soc., 2012, 134, 19489-19497; (e) Q. Duan, Y. Cao, Y. Li, X. Hu, T. Xiao, C. Lin, Y. Pan and L. Wang, J. Am. Chem. Soc., 2013, 135, 10542-10549; $(f)$ G. Yu, Y. Ma, C. Han, Y. Yao, G. Tang, Z. Mao, C. Gao and F. Huang, J. Am. Chem. Soc., 2013, 135, 10310-10313.

8 (a) H. Li, D.-X. Chen, Y.-L. Sun, Y. B. Zheng, L.-L. Tan, P. S. Weiss and Y.-W. Yang, J. Am. Chem. Soc., 2012, 134, 1570-1576; (b) Y. Yao, M. Xue, X. Chi, Y. Ma, J. He, Z. Abliz and F. Huang, Chem. Commun., 2012, 48, 6505-6507; (c) D.-X. Chen, Y.-L. Sun, Y. Zhang, J.-Y. Cui, F.-Z. Shen and Y.-W. Yang, RSC Adv., 2013, 3, 5765-5768; (d) M.-m. Tian, D.-X. Chen, Y.-L. Sun, Y.-W. Yang and Q. Jia, RSC Adv., 2013, 3, 22111-22119.

9 (a) Z. Niu, F. Huang and H. W. Gibson, J. Am. Chem. Soc., 2011, 133, 2836-2839; (b) L. Chen, Y.-K. Tian, Y. Ding, Y.-J. Tian and F. Wang, Macromolecules, 2012, 45, 8412-8419; (c) Y. Ding, P. Wang, Y.-K. Tian, Y.-J. Tian and F. Wang, Chem. Commun., 2013, 49, 5951-5953; (d) N. L. Strutt, D. Fairen-Jimenez, J. Iehl, M. B. LaLonde, R. Q. Snurr, O. K. Farha, J. T. Hupp and J. F. Stoddart, J. Am. Chem. Soc., 2012, 134, 17436-17439.

10 T. Mitra, K. E. Jelfs, M. Schmidtmann, A. Ahmed, S. Y. Chong, D. J. Adams and A. I. Cooper, Nat. Chem., 2013, 5, 276-281.

11 (a) O. Green, S. Grubjesic, S. Lee and M. A. Firestone, Polym. Rev., 2009, 49, 339-360; (b) J. Lu, F. Yan and J. Texter, Prog. Polym. Sci., 2009, 34, 431-448; (c) J. Yuan, D. Mecerreyes and M. Antonietti, Prog. Polym. Sci., 2013, 38, 1009-1036.

12 (a) J. E. Bara, D. E. Camper, D. L. Gin and R. D. Noble, Acc. Chem. Res., 2010, 43, 152-159; (b) J. Yuan, S. Soll, M. Drechsler, A. H. E. Mueller and M. Antonietti, J. Am. Chem. Soc., 2011, 133, 17556-17559; (c) M. Lee, U. H. Choi, S. Wi, C. Slebodnick, R. H. Colby and H. W. Gibson, J. Mater. Chem., 2011, 21, 12280-12287; (d) Q. Zhao, T.-P. Fellinger, M. Antonietti and J. Yuan, Macromol. Rapid Commun., 2012, 33, 1149-1153; (e) Q. Zhao, M. Yin, A. P. Zhang, S. Prescher, M. Antonietti and J. Yuan, J. Am. Chem. Soc., 2013, 135, 5549-5552; $(f)$ U. H. Choi, A. Mittal, T. L. Jr. Price, H. W. Gibson, J. Runt and R. H. Colby, Macromolecules, 2013, 46, 1175-1186.

13 (a) Q. Zhao, P. Zhang, M. Antonietti and J. Yuan, J. Am. Chem. Soc., 2012, 134, 11852-11855; (b) Q. Zhao, S. Soll, M. Antonietti and J. Yuan, Polym. Chem., 2013, 4, 2432-2435.

14 A. F. Thunemann, M. Muller, H. Dautzenberg, J. F. O. Joanny and $\mathrm{H}$. Lowen, Polyelectrolyte complexes, in Polyelectrolytes with Defined Molecular Architecture II, ed. M. Schmidt, Advances in Polymer Science 166, Springer, Berlin, 2004, pp. 113-171. 